\title{
ENTRE O “RESPIRAR" DAS MÁQUINAS E O RESPIRAR DA VIDA: O DISCURSO DA ESSENCIALIDADE DA MINERAÇÃO E O DIREITO DE VIVER EM TEMPOS DE PANDEMIA
}

\begin{abstract}
Between the "breathing" of machines and the breathing of life: the discourse of the essentiality of mining and the right to live in times of pandemic

La "respiración” de las máquinas y la respiración de la vida: el discurso de la esencialidad de la minería y el derecho a vivir en tiempos de pandemia
\end{abstract}

Poliana de Sousa Nascimento ${ }^{1}$

\begin{abstract}
Resumo:
Com esse artigo, pretendo realizar apenas uma reflexão e instigar novos formas de pensar sobre o discurso da essencialidade da mineração a partir de informações noticiadas nesses tempos de pandemia do Coronavírus e como a classificação do que é essencial se apresenta para o mercado de produção mineral e para Estado. Como parte dessa discussão ressalto a importância em se entender como povos e comunidades tradicionais, com destaque para indígenas e quilombolas, são entendidas nesse processo mineral, destacando a negligência atribuída aos seus corpos e ao direito de, literalmente, respirar em seus territórios.
\end{abstract}

Palavras-chave: Essencial, Mineração, Estratégia, Pandemia.

\begin{abstract}
:
The article is part of a reflection of new ways of thinking about the discourse on the essentiality of mining reported in these times of the Coronavirus pandemic and how the classification of what is essential for the mineral production market is presented. Moreover, I emphasize the experiences of traditional peoples and communities, especially indigenous and quilombola, marginalized in this mineral exploration process, their bodies and the right to breathe in their territories.
\end{abstract}

Keywords: Musical field; Covid-19 in Manaus; Power relations; Music

\footnotetext{
${ }^{1}$ Antropóloga. Doutoranda em Antropologia pela Universidade Federal de Pernambuco - UFPE. Pesquisadora do Projeto Nova Cartografia Social da Amazônia - PNCSA. E integrante do Laboratório de Estudos sobre Ação Coletiva e Cultura - LACC/UPE e do Grupo de Estudos Socioeconômicos da Amazônia - GESEA/UEMA.
} 


\section{Resumen}

El artículo es parte de una reflexión de nuevas formas de pensar sobre el discurso acerca de la esencialidad de la minería reportada en estos tiempos de la pandemia de Coronavirus y cómo se presenta la clasificación de lo esencial para el mercado de producción de minerales. Todavia, enfatizo los pueblos y comunidades tradicionales, especialmente indígenas y quilombolas, en este proceso mineral, sus cuerpos y el derecho a respirar en sus territorios.

Palabras clave: Esencial, Minéria, Estrategia, Pandemia.

\section{Introdução}

O cenário pandêmico que tomou conta do mundo e que no Brasil, se intensificou com força imensurável, tem exposto o retrato da nossa fragilidade que só vem expor velhos problemas, reflexo de um esquecimento planejado atribuído ao Estado diante do não agir em meio a um caos existente. A pandemia do Coronavírus agravou ainda mais a desestruturação da saúde e dos programas sociais que já estavam em desmonte em função de uma crise política anunciada desde 2013 e que hoje se apresenta bem mais evidente.

Há em torno dessa questão, o discurso de falta de recursos atribuído pelo Estado para dar conta das proporções tomadas pela pandemia no país e ausência desse mesmo Estado nas ações que deveriam amenizar as consequências dessa pandemia; mas há também um discurso da "salvação" que pode não chegar diretamente do Estado, porém chega, por meios de outras iniciativas. Ou seja, a partir de setores privados que legitimam suas práticas em torno também do discurso de desenvolvimento e que em tempos de pandemia, o fazem em favor do direito à vida das pessoas. Compondo dessa maneira, um enunciado que se volta para a essencialidade de suas atividades a partir dos seus interesses para se manterem no controle.

Por essencialidade, em alguns dicionários, é compreendido como aquilo que é imprescindível, que é muito necessário e que não pode ser deixado de lado ou ignorado. Quando a essencialidade é atribuída apenas aos aspectos econômicos, como é o caso da mineração no Brasil, se perde o que poderia ser uma abordagem válida da continuidade das atividades minerais e se tira a compreensão de um lugar de amplitude que carrega essa classificação. Há um discurso alinhado que caracteriza o que é urgente, necessário e essencial. Porém, a finalidade do que é enunciado se articula a partir de estratégias sociais para legitimar a prática mineral e justificar a continuidade da produção frente a um mercado produtivo.

O "discurso da salvação" vem acompanhado aqui de uma tecnologia do poder. Tecnologia que permite o controle de populações inteiras e que Foucault (2012) vai identificar como uma biopolítica do poder. E que para o contexto de pandemia com olhar direcionado à povos e comunidades tradicionais, se converge para um entendimento de um processo de colonialidade. Isso é resultante de uma colonização que marca, especialmente corpos de povos e comunidades de forma marginal e racializada em condição constante de vulnerabilidade, destacando uma rede de poder que se articula para possibilidade de uma necropolítica (Mbembe, 2020). Ou porque não, uma bionecropolítica(LIMA, 2018). Quer dizer, não significa de fato uma expressão de preocupação com a vida, mas pelo controle do corpo e das formas de matar.

Será a partir de reflexões minhas obtidas a partir do que noticiou a cerca da pandemia e mineração que buscarei realizar também uma abordagem da regulação do corpo e da vida por meio de mecanismos estratégicos de poder. Principalmente porque entendo que tal abordagem é justificada por meios de ações do Estado e das empresas mineradoras de forma racional, e que coloca na linha de frente uma ideia protecionista e, paradoxalmente, do direito de matar. Compondo essa questão, buscarei permeá-la em torno de uma dis- 
cussão que se volta para a promoção do desenvolvimento latente mesmo em tempos de pandemia noticiadas nas agências de promoção mineral. Enfatizando formas de morrer e de matar (ZKOURI, 2014) promovidas por um projeto de desenvolvimento e de crescimento econômico que não agrega os interesses de todos.

\section{"A mineração não pode parar"}

Os investidores da mineração dizem aos quatro ventos “a mineração não pode parar". Há, em meio à pandemia do Coronavírus uma produção de marketing para trazer uma outra cara para a mineração e mostrar a sua essencialidade. Por que o agro pode ser pop e a mineração não? E a "ideia de que a produção da imagem sobre a mineração chega nas pessoas comuns de forma errônea e sem que seja dada a devida importância à sua essencialidade" (DEBIAZZI, 2019). E apoiados nisso, o discurso se ampliação da fronteira mineral no Brasil se justificam pela necessidade de produzir o que é essencial e para se manter no mercado de produção (DEBIAZZI, 2019).

A indústria da mineração cumpre, nesse momento caótico, uma missão estratégica de promoção de suas atividades para o crescimento econômico a partir de um processo filantrópico que visa promover o mantimento da segurança da população. Com destaque para um discurso de essencialidade das atividades em torno da geração de empregos e garantia da vida a partir de grandiosas doações destinados a financiamentos de missão estratégica na promoção do crescimento econômico e para o financiamento de políticas públicas inclusivas e transformadoras para a necessidade de profunda reflexão sobre a indústria da mineração. Tudo isso para garantir segurança à população e assegurar contribuição social aos municípios e estados que recepcionam a atividade mineradora.

Apontam, igualmente, para a essencialidade de preservação de uma indústria que produz crescimento econômico e avanço social. Tornando a atividade que nesse momento de cenário econômico agravante, uma possiblidade de crescimento. Há um discurso de engrandecimento da atividade em torno do que pode ser rentável para o país, "pois a mineração gera para o Brasil $4 \%$ do Produto Interno Brasileiro (PIB), por 21\% das exportações, com geração de quase 200 mil empregos diretos e mais de dois milhões de indiretos" (ROSCOE, 2019). De forma que o freamento das atividades agravaria ainda mais o setor comercial e de geração de empregos em uma crise onde se precisa cada vez mais de tributos para garantir ações que viabilizem a controle da pandemia. Contudo, quando se fala em extração mineral, essa se difere das ações de uma indústria extrativa, "pois nessa indústria extrativa entra também as ações petrolíferas e a partir dessa se justifica os $4 \%$ do PIB, sendo, a atividade mineral equivale apenas a $1 \%$ do PIB no Brasil”2.

O controle aparece aqui como o próprio controle da economia, mas também dos dispositivos de saúde que deveriam ser garantidos pelo Estado. Há uma artimanha que é articulada em torno de ações humanitárias, uma vez que grandes empresas mineradoras, entram na corrida para expansão de seus negócios e para se manter no mercado internacional, a partir de medidas sociais associadas ao fretamento da crise em torno da pandemia. Como a empresa Vale que trouxe ao Brasil 5 milhões de kits de testes rápidos como ajuda para o governo Brasileiro (VALE, 2020).São intivestimentos que chegam aos cofres públicos a partir de amarras que articulam as relações de poder que se estabelecem entre Estado e grandes empreendimentos econômicos. Porque a maneira como as ações minerais são estabelecidas anula outras formas de entendimento sobre a prática mineral sem mesmo considerar outros argumentos.

A construção do discurso da essencialidade nos chega a partir do que se convencionou a ser exaltado a partir de números, nos é induzida a partir de uma contagem de valores que perpassam por relações

\footnotetext{
${ }^{2}$ Declaração dada em entrevista à Silvia Noriko Tagusagawa em sua pesquisa de doutorado em 2015.
} 
políticas, de poder e de desigualdades no contexto do capitalismo global, mas que a ênfase não é definitivamente captada para ser pensada a partir desse horizonte. Tampouco se dá ênfase às transformações socioambientais que podem vim no combo das ações minerais, e que são completamente ignoradas. A valorização da essencialidade é justificada pela valorização econômica capitalista de apropriação da natureza e de territórios legalmente usurpados.

Legalmente, porque o caráter de legalidade é atribuída a prática de mineração antes mesmo da promulgação da Constituição Federal de 1988, com o Decreto 3.365/1941 - um ano antes da criação da então Vale do Rio Doce, hoje Vale S.A - que dispõe sobre utilidade pública para fins de desapropriação de áreas para extração de minérios, expressamente no inciso " $\mathrm{f}$ " do Art. $5^{\circ}$, e considerada a partir disso, a mineração como de utilidade pública.

Há uma reorganização do território que não é "puramente um mecanismo mecânico da expansão das trocas, mas das políticas apresentadas que se articulam em torno de reestruturação do mercado, disciplinando a comercialização da terra e dos recursos naturais. De uso do solo e de subsolo". (ALMEIDA, 2017, p.120). Dessa forma, há uma tentativa constante de redução de territórios tradicionais a partir, por exemplo, da redução de áreas propostas para titulação, procrastinação da titulação definitiva de terras quilombolas, ausência de medidas quanto ao desintrusamento de terras indígenas e redução de terras indígenas.

E as ações do Estado são completamente aliadas nesses arranjos jurídicos para "flexibilizações da legislação que favoreçam as ações minerais, apoiadas, sobretudo em políticas de crescimento apontadas para solucionar a "pobreza extrema" em áreas consideradas "em desenvolvimento" (ALMEIDA, 2017). Como por exemplo, a portaria 135 emitida pela MME - Ministério Minas e Energia que inclui o setor de mineração entre as atividades consideradas essenciais, de acordo com o Decreto 10.329, de 28 de abril de 2020 no período referente à pandemia da COVID-19. Tal medida destaca que a continuidade das atividades I - pesquisa e lavra de recursos minerais, bem como atividades correlatas; II - beneficiamento e processamento de bens minerais; III - transformação mineral; IV - comercialização e escoamento de produtos gerados na cadeia produtiva mineral; e V - transporte e entrega de cargas de abastecimento da cadeia produtiva(BRASIL, 2020).

Há uma tentativa do Estado em dá outros significados para atividades que compreendem grandes extensões de terra, inclusive no que diz respeito a direitos territoriais e expansão de terras para implementação de conglomerados econômicos. A esse discurso, segue a problemática de tratar essas questões com "um viés "protecionista" imbuído de uma justificativa desenvolvimentista e que seguem compasso dos interesses do agronegócio", pois a mineração é ao lado do agronegócio a base da economia brasileira (ALMEIDA, 2017). Contudo, a primeira recebe o caráter de ser "pop" e a segunda busca ao longo dos anos um lugar de prestigio a partir de suas "campanhas verdes" para ter sucesso no mercado de capitais.

Nesses tempos de pandemia, o setor mineral vem com uma abordagem midiática forte e de visibilidade que garantam a esse setor outra perspectiva identitária. O caráter de essencialidade vem acompanhado de uma tentativa de fortalecer sua legitimidade a partir do minério que faz parte do cotidiano de todos e está presente na vida das pessoas.

Isso porque a ideia de desenvolvimento é naturalizada pelo crescimento econômico e que a industrialização e o uso dos recursos naturais é um processo inevitável. Se por um lado há uma legitimidade do discurso da empresa pelo Estado, pois nesse há, como ressalta Bourdieu (2014. p.46)" uma política dentro do mundo que nos rege reconhecida como legitima porque ninguém questiona a possibilidade de fazer de outra maneira e porque não é questionada", por outro, falta um debate político em torno da desnaturalização do desenvolvimento imposto e posto.

No caso da pandemia há uma evocação de outras formas de se pensar o bem estar e da vida que é do outro, mas esse pensamento dispõe de um entendimento que é vinculado especialmente com o dos 
lucros que se gera em torno do cenário existente. O Estado, em conformidade com as empresas, cria uma ideia de entidade e de um aparelho burocrático de gestão de interesses coletivos, contudo, não há equidade na forma de agir, nem de considerar os bens naturais e o modo como esse bem reflete no ambiente. Afinal, quem são os sujeitos que participam dessa coletividade e que estão à margem do capital?

O setor mineral, tal como o do agronegócio atua em torno de uma "ação intersetorial que envolve empresas locais e internacionais, industriais e serviços relacionados à mineração, relações de política local e esse conjunto de bloco de caráter político que atua de forma também coordenada, tal como o agronegócio e totalmente institucionalizada”. (POMPEIA, 2018). É a esse conjunto de ações que Pompeia (2018) denomina de concertação política. Sua finalidade principal é convencer a opinião pública a valorizá-la e pressionar o Estado a inseri-la como elemento estratégico no planejamento governamental (POMPEIA, 2018). E agrega o que o antropólogo Alfredo Wagner chamaria de "agroestratégias", fazendo referências às estratégias arquitetadas por grandes conglomerados econômicos que agregam grandes corporações econômicas.

No caso da mineração, que é conhecida por suas violações dos direitos humanos, se munem de uma estratégia baseada em um "risco social corporativo" (GIFFONI, 2019) que são influências exercidas pelas empresas a partir de políticas sociais que garantem apoio do Estado a partir das instituições reguladoras. Com a pandemia essas políticas de responsabilidade corporativa se tornaram ainda mais evidentes por conta dos mecanismos de convencimento e de apoio às comunidades por meio do marketing e propaganda para garantir a licença social para operar e esse é o objetivo das empresas.

E há com essa explanação uma abordagem que se volta para o processo de acumulação de um capital que não se ver. Segundo estudo da ONG Oxfam, entre 18 de março e 12 de julho, o patrimônio dos 42 bilionários do Brasil passou de US\$123,1 bilhões para US\$ 157,1 bilhões (OXFAM, 2020). E tudo isso acontece quando o número de desempregados sobe de 9 para 12 milhões de pessoas (IBGE, 2020). Estão entre esses que se tornaram mais ricos empresários do ramo de bancos, mineração, bebidas e planos de saúde. (OXFAM, 2020)

O corpo humano ganha nessa dimensão econômica com ou sem pandemia, um caráter de inutilidade e de falta de valor. Pois a atividade mineral é sozinha, responsável pela piora da qualidade de vida de trabalhadores e de quem vive nos entornos de suas minas. A crise sanitária vem como um agravante da situação, que através das ameaças de punições - perda de emprego e diminuição de salários - coloca os trabalhadores reféns de um capitalismo do qual estão à margem.

O saber associado às relações de economia colabora para que um certo tipo de poder seja estabelecido e exercido em torno de saber e de acesso às informações que não estão ao alcance de todos. Para Foucault: "O poder produz saber e não há relação de poder sem constituição correlata de um campo de saber, nem saber que não suponha e não constitua ao mesmo tempo relações de poder" (FOUCAULT, 2010)”.

Alguns meses se passaram desde o início da pandemia no país e o medo mede o termômetro do controle estabelecido pelo capital e pelo crescimento dos lucros negociados pelas empresas mineradoras que tira um bem que é universal, que é a respiração. Como destaca Mbembe (2020)"O direito universal à respiração não é quantificável. Não é apropriável. É um direito relativo à universalidade, não apenas de cada membro da espécie humana, mas do vivo na sua totalidade".

O direito à existência é nesse contexto pandêmico, negado por interesses impulsionados pela promoção do medo. Se banaliza a vida, e também o sofrimento. Mas esses são aspectos do controle que sempre estiveram na ordem do dia quando se trata de ações do Estado e de empresas que buscam expandir suas atividades, pois mesmo antes da pandemia, o cenário geopolítico sempre foi agressivo para quem está à margem do capital, especialmente, povos e comunidades tradicionais. 


\section{Até o último suspiro}

Antes mesmo que pudéssemos pensar em uma crise sanitária mundial que, em passos lentos, chegava ao Brasil e se alastrava por todo o território nacional de maneira avassaladora, já estávamos aqui em uma crise política e de intensa violação de direitos. Sobretudo, quando o assunto se volta para povos e comunidades tradicionais. Os vários PLs, como a PL490/2007³ sobre o marco temporal e a mais recente 191/2020 $0^{4}$ que viabiliza e regulamenta a exploração de recursos minerais, hídricos e orgânicos em reservas indígenas, que violam o direito de vida desses grupos tradicionais vem de outros tempos e se intensificam no ato dessa grande crise pandêmica.

Obviamente, tanto uma como a outra só reverberam para o entendimento de que tais interesses tem como finalidade eliminar ou modificar os direitos conquistados por povos indígenas. Com ações de desmontes vindas especialmente do governo federal atual, a pandemia só agravou a desestruturação dos setores da saúde, de programas sociais e de educação que estava em desconstrução. Diga-se de passagem, itens básicos e de direito para a manutenção da vida das pessoas em sociedade.

Além da desorganização de órgãos que se direcionavam para a resolução de assuntos ligados às questões indígenas - FUNAI (Fundação Nacional do Índio) e extinção de secretarias ligadas aos assuntos quilombolas. Houve ainda a tentativa de extinção do conselho distrital - SESAI (Secretaria Especial de Saúde Indigena) pelo decreto 9759 e uma ação intensificada para o desarmamento dos dispositivos jurídicos que poderia garantir acesso à uma reivindicação legal.

Com SESAI e FUNAI em processo de desestruturação promovidos pelo próprio governo, quem assume as "responsabilidades" que deveriam garantir a vida desses grupos? Há de fato um projeto político de morte que são reflexos de um "descaso planejado" (SCOTT, 2009) com vistas de promoção de um controle dos territórios e dos corpos e que acompanha ações intersetoriais que estão deste os atos do Estado às práticas de expansão dos grandes projetos de desenvolvimento e econômicos no país.

Mas em se tratando especialmente da pandemia do Coronavírus que nos assola e dos corpos que sentem de fato as consequências dessa crise, há um processo de colonialidade que resulta de uma colonização que marca corpos de povos e comunidades, especialmente as tradicionais, em constante situação de vulnerabilidade. A vulnerabilidade sempre esteve à espreita nesses grupos que, com ou sem pandemia, estiveram à margem do que se pode considerar bem viver. E como dispõem e reivindicam um território de direito, estão eles à mercê dos ataques e dos conflitos eminentes e nunca cessantes em torno de seus territórios.

Há sempre uma tentativa de controle, não somente sobre seus territórios, mas sobre seus corpos. Foucault (2012) destaca o conceito de biopoder e como o Estado faz uso desse recurso para controlar o corpo dos indivíduos em "torno da gestão da saúde, da higiene, da alimentação, da sexualidade, da natalidade, dos costumes". O termo "bio" nos permite pensar em vida, em manter uma vida. No entanto, o biopoder nos permite analisar essa vida a partir do controle que pode existir em torno dela.

\footnotetext{
${ }^{3}$ Proposta ruralista que altera a Lei $n^{\circ}$ 6.001, de 19 de dezembro de 1973, que dispõe sobre o Estatuto do Índio; ou seja, Ele também insere no Estatuto do Índio - que data de 1973 - a tese do marco temporal, segundo a qual os povos indígenas só teriam direito à demarcação das terras que estivessem sob sua posse em 5 de outubro de 1988, data da promulgação da Constituição Federal.

${ }^{4}$ Regulamenta o § 1ㅇdo art. 176 e o § 3ㅇdo art. 231 da Constituição para estabelecer as condições específicas para a realização da pesquisa e da lavra de recursos minerais e hidrocarbonetos e para o aproveitamento de recursos hídricos para geração de energia elétrica em terras indígenas e institui a indenização pela restrição do usufruto de terras indígenas. O Projeto de Lei 191/20 regulamenta a exploração de recursos minerais, hídricos e orgânicos em reservas indígenas. (CAMARA DOS DEPUTADOS, 2020)
} 
Ele permite o controle de populações inteiras. Em uma era onde o poder deve ser justificado racionalmente, o biopoder é utilizado pela "ênfase na proteção de vida, na regulação do corpo, na proteção de outras tecnologias" (FOUCAULT, 2012). E apesar de existir um biopoder que rege ações que se articulam entre as grandes empresas, há mais ainda uma negociação em torno da possibilidade do matável e que constitui como organizador das relações sociais capitalistas.

Achille Mbembe (2020) destaca em seus escritos o biopoder enfatizado por Foucault, mas questiona se essa noção é capaz de designar práticas contemporâneas pela aniquilação do "inimigo" como objetivo prioritário. Ele destaca que estamos em uma guerra, guerra essa que não constitui apenas um meio para garantir soberania, mas para exercer o direito de matar. $\mathrm{O}$ "direito de punir sem qualquer discrição na arte de fazer sofrer" (FOUCAULT, 2012, p.12).

Há um assassino sem rosto, mas o corpo, esse apresenta um padrão com lugar reservado para a vida ou para a morte. O direito à vida é subtendido em uma sociedade com o direito de matar legitimado e é esse direito de matar que Mbembe (2020) denomina necropolítica, pois para ele o racismo é o seu principal motor e impulsionador dos atos do Estado.

Entrar nessa questão teórica sobre o biopoder e sobre necropolítica me parece pertinente, entendendo principalmente que durante uma crise sanitária, enquanto os corpos dos brasileiros padecem sem acolhimento, não lhe é garantido nem ao menos o direito de respirar. Mbembe (2020) enfatiza que "sem dúvida, estamos vivemos em tempos onde o respirar está sendo cada vez um fator de percepção e de consciência que não tínhamos antes, sobretudo, porque está intrínseco ao ato de viver". Porém um vírus que, através de um processo acelerado de destruição, nos asfixia e mata, só reforça uma conjuntura defasada pela indiferença.

Os povos e comunidades tradicionais sempre estiveram no meio do caminho quando o assunto é desenvolvimento ou expansão de fronteiras de desenvolvimento. E quando o assunto é esse, envolve inevitavelmente seus territórios de direito. Por território de direito se entende aquele que que possui "sujeitos sociais com existencia coletiva" (ALMEIDA, 2013, p.32). O que torna todos esses povos e comunidades destinatários da Convenção 169.

A convenção determina que seja realizada consulta de caráter prévio, livre e informado para quaisquer intervenções nos territórios e modos de vida desses segmentos. (Convenção 169/OIT, 2011). Há, contudo, "tentativas de deslegitimação ou de redução de sua amplitude que segue também a linha da omissão e da falta de informação que não chega a quem interessa saber sobre o Decreto". E quando ocorre, se dá por vias duvidosas, com uma simples reunião ou uma audiência pública que não tenha a intervenção da comunidade envolvida. (TERRADEDIREITO, 2020)

A boa fé parece não existir e a violação dos direitos se faz sobretudo em uma crise pandêmica, pois é quando os fatores de vulnerabilidades se tornam ainda mais evidentes, demonstrando os aspectos de fragilidade que podem existir e que se acirram como fogo porque a regra é uma só: a sobrevivência. Há com a pandemia uma oportunidade para continuidade de atividades econômicas por empreendimentos, sobretudo, da mineração com o discurso da essencialidade. E como o vírus não se limita às fronteiras, o aumento do registro de casos da Covid-19 que se tem registrado nos territórios da mineração tem afetado substancialmente povos e comunidades tradicionais em todo território brasileiro.

É um genocídio planejado e articulado. Vem pelo caminho do corpo, daquilo que nos é essencial na vida: o respirar. Mas se por um lado há um avanço das atividades econômicas, há também uma rede de movimentos sociais que se articula entre plataformas digitais e que por meio de denúncias se organizam para diminuírem as agressões sofridas. A Coordenação Nacional de Articulação das Comunidades Quilombolas- (CONAQ), que monitora a evolução da Covid-19 nos quilombos do Brasil de forma autônoma, se articula em uma rede consistente de apoio e que agrega organização de outros estados 
brasileiros. Há em seus registros que datam de junho/2020, 721 caso confirmados entre quilombolas, 77 óbitos, 2 óbitos suspeitos sem confirmação, com 190. (TERRADEDIREITO, 2020)

Tal como ocorre com os quilombolas, os indígenas também estão nessa frente de articulação e através da Articulação dos Povos Indígenas do Brasil (APIB) denuncia o alastramento da doença nos territórios indígenas, inclusive agravadas pela continuidade das atividades de empreendimentos do agronegócio e mineração, já contabilizando 211 óbitos, apontando para uma taxa de 15\% de letalidade. (TERRADEDIREITO, 2020)

Não há um plano de contenção diante da pandemia direcionado ao país, tampouco um plano específico que considere a realidade de povos e comunidades tradicionais. Em contrapartida, o governo federal no auge de suas atividades promove reuniões ministeriais, cujo o assunto em questão, a pandemia, é pensando por uma perspectiva condenável, expressados a partir de um de ..."aproveitar a pan-

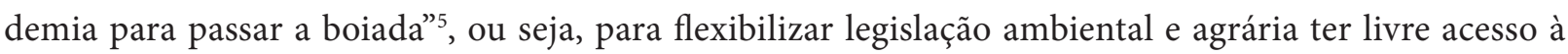
exploração dos biomas, recursos e territórios tradicionalmente ocupados, repudiando os modos de vida dos povos tradicionais e ferindo o direito à vida, à saúde e à integridade.

A postura do Estado tem sido, a partir das medidas pensadas para a situação d pandemia, de relativizar a consulta prévia. É um caso de conjunto de violações de direitos fundamentais, como direito à saúde, à vida, à consulta e à dignidade humana. Há relativização do direito à vida pelos governos e a iniciativa privada devido a continuidade das atividades de empreendimentos de infraestrutura, mineração, agronegócio, inclusive dentro de territórios tradicionais, agravando a contaminação pela Covid-19. O governo de Jair Bolsonaro lança a campanha de que "O Brasil não pode parar", que a economia não pode estacionar, ferindo orientações da Organização Mundial de Saúde (OMS) que já atestou o isolamento social como meio mais eficaz para contenção da pandemia. Há violação das orientações internacionais no campo da saúde e da consulta prévia pela continuidade ou liberação de atividades não essenciais nesse contexto.

Há, sobretudo, em meio a toda a construção de crise uma naturalização tecnológica do crescimento econômico, de que a industrialização da forma que acontece é inevitável e inquestionada. E de que o caráter "tradicional" ainda precisa ser superado, como se este representasse o reflexo do atraso, quando na verdade constitui um modo de vida diferenciado e com especificidades de saberes. A ausência do debate politico em torno dessa naturalização do sentido de desenvolvimento, especialmente, quando se trata da mineração, é que precisa ser discutido.

Tudo passa a ter um valor de mercado. Tudo passa a ser também controlado, ou caminhando para um controle não somente do mercado, mas dos corpos. E como o desenvolvimento é entendido a partir das lógicas das empresas e do Estado em ações que partem de uma concertação política, enfatizada por Pompeia, mas sem desnaturalizar a noção de política que aí está posta. Frases como "Brasil não pode parar" trazem em seu contexto uma gama de significado e de padrões políticos que se repetem. São histórias que se contam da mesma forma e na mesma fôrma e o cenário não muda contando as mesmas histórias.

\section{Considerações finais}

Finalizo, enfatizando que o contexto de pandemia do Coronavírus não se justifica por si só. As crises que estão para além da pandemia, marcam a história, os territórios e os corpos de grupos que, considerados vulneráveis, se reinventam para respirar, para sobreviver. Nossa sociedade é desigual, e culturalmente diversa, há uma riqueza que é biosociocultural e níveis extremos de desigualdade que sempre estiveram evidentes e

\footnotetext{
${ }^{5}$ A frase destacada refere-se a fala do então ministro do meio ambiente, Ricardo Salles, sobre aproveitar o momento de crise provocada pela pandemia pra mudar regras ligadas à proteção ambiental e à área de agricultura enquanto a atenção da mídia se voltava apenas para a Covid-19.
} 
que não são contemplados em um sistema cujo o poder das relações é medido pelo valor de mercado. A rigor, não há um plano de ação em torno do bem viver desses grupos. Há um modelo político econômico que cresce a partir do agronegócio e da extração de commodities minerais, pois ambos andam juntas quando se trata de expandir territórios para ampliação dessas atividades.

Não se está dizendo aqui que a atividade da mineração não seja de utilidade pública, ao contrário, muito que consumidos hoje e nos acostumamos a consumir são insumos necessários para a sociedade moderna que se construiu desde que se iniciou o período de revolução industrial. Para tanto, em meio a um cenário caótico da estrutura de governo e lamentavelmente, isso nos vem acompanhando de uma pandemia global, são as empresas e aqui, enfatizo as empresas mineradoras, que saem ganhando, sem qualquer sinal de arranhão.

E esse é o novo mundo, que não é tão novo assim, que nos é apresentado. Com um sistema informacional e de desenvolvimento que não pertence a maior parte da população e nem aos grupos tradicionais. O conhecimento, que aqui se apresenta por tecnológico, passa a ser uma apropriação necessária para o desenvolvimento dessa nova abordagem do capital que tem na "filantropia tóxica", um rosto cada vez mais presente e atuante. "Grande parte do mercado mundial das commodities que está nas do setor financeiro e não de uma economia real"' (DOWLOR, 2020) para mostrar que o caminho para se sair de uma crise, seja ela qual for, está nas mãos de grandes empresas que promovem uma insustentabilidade de um sistema que sufoca qualquer possibilidade de soberania de povos e comunidades tradicionais, banaliza sua vida e sua morte e promovem através do sofrimento a incerteza do amanhã.

\section{Referências}

ALMEIDA, Alfredo Wagner Berno de. Povos e comunidades tradicionais entre os novos significados de território e de rito de passagem da "proteção" ao "protecionismo". Agroecologia e diálogo de conhecimento: olhares de povos e comunidades tradicionais, movimentos sociais e academia. Recife: UFRPE, 2017. p.119-131

BOURDIEU, Pierre. Sobre o Estado. São Paulo: Companhia das Letras, 2014.

Convenção $n^{\circ} 169$ sobre povos indígenas e tribais e Resolução referente à ação da OIT / Organização Internacional do Trabalho. - Brasilia: OIT, $20111 \mathrm{v}$.

DEBIAZZI, Daniel. A mineração é essencial para quem?. Brasil Mineral, 2019. Disponível em <https:// www.brasilmineral.com.br/noticias/minera\%C3\%A7\%C3\%A3o-\%C3\%A9-essencial-para-quem>.

ROSCOE, Flávio. Nova mineração. FIEMG. 2020. Disponível em <https://www7.fiemg.com.br/iel/Noticias/Detalhe/nova-mineracao $>$. Acesso em 5 de maio de 2020.

FOUCAULT, M. A Arqueologia do saber. Rio de Janeiro: Forense Universitária, 2013.

FOUCAULT, Michel. Vigiar e punir: nascimento da prisão; tradução de Raquel Ramalhete. Petrópolis, RJ: Vozes, 2012.

FOUCAULT. M. A ordem do discurso. São Paulo: Editora Loyola, 2010.

\footnotetext{
${ }^{6}$ Fala do professor Ladislau Dowlor em palestra O capitalismo se desloca: novas arquiteturas sociais realizada pelo Sesc São Paulo proferida em live. 2020. Disponível em < https://www.youtube.com/watch?v=HN8LXk4lwkA >
} 
GIFFONI, Raquel. Conflitos ambientais, corporações e as politicas de risco. Rio de Janeiro: Garamond, 2019.

IBGE. Instituto Brasileiro de Geografia e Estatistica,2020. Disponível em https://www.ibge.gov.br/explica/ desemprego.php

LIMA, Fátima. Bionecropolítica: diálogos entre Michel Foucault e Achille Mbembe. Rio de Janeiro: Arquivos Brasileiros de Psicologia; 2018.p 20-33.

MBEMBE, Achille. O direito universal à respiração. Instituto Humanitas Unisinos. Disponivel em $<\mathrm{http}: / /$ www.ihu.unisinos.br/78-noticias/598111-o-direito-universal-a-respiracao-artigo-de-achille-mbembe >. Acesso em 30 de abril de 2020.

BRASIL. Ministério de Minas e Energia. Portaria No 135/GM, de 28 de março de 2020.

OXFAM. Quem paga a conta? Taxar a riqueza para enfrentar a crise da Covid-19na América Latina e Caribe. 2020 https://www.oxfam.org.br/justica-social-e-economica/quem-paga-a-conta/ Acesso em 04 de setembro de 2020.

POMPEIA, Caio. A concertação de política do agronegócio e os direitos territoriais indígenas e quilombolas. Caxambu - MG. Anpocs, 2018.

SCOTT, Parry. Negociações e resistências persistentes: agricultores e a barragem de Itaparica num contexto de descaso planejado. Ed. Universitária da UFPE: Recife, 2009.

TERRA DE DIREITO. Como fica o direito à consulta prévia no contexto da pandemia? . Disponivel em $<$ https://terradedireitos.org.br/covid19/artigos/como-fica-o-direito-a-consulta-previa-no-contexto-da-pandemia/23405>. Acesso em 04 de setembro de 2020.

VALE. Vale traz ao Brasil 5 milhões de kits de testes em ajuda humanitária no combate ao novo coronavirus. 2020. Disponível em <http://www.vale.com/brasil/PT/aboutvale/news/Paginas/vale-traz-ao-brasil-5-milhoes-de-kits-de-testes-em-ajuda-humanitaria-no-combate-ao-novo-coronavirus.aspx $>$.

ZHOURI, Andrea. ZHOURI, Andréa; VALENCIO, Norma (Org.). Formas de matar, de morrer e de resistir: limites da resolução negociada de conflitos ambientais. Belo Horizonte: UFMG, 2014.

Recebido em 22/09/2020

Aceito em 06/10/2020 